\title{
The Flory-Huggins Interaction Parameter and Thermoreversible Gelation of Poly(vinylidene fluoride) in Organic Solvents
}

\author{
Masaru OKABE, Risei WADA, Michiko TAZAKI, and Terutake HommA \\ Department of Applied Chemistry, Faculty of Engineering, Kanagawa Institute of Technology, \\ 1030 Shimo-ogino, Atsugi, Kanagawa 243-0292, Japan
}

(Received May 22, 2003; Accepted August 6, 2003)

\begin{abstract}
The Flory-Huggins interaction parameter $\left(\chi_{12}\right)$ between poly(vinylidene fluoride) (PVdF) and organic solvent was estimated experimentally over wide range of temperature by an inverse gas chromatography (IGC) using many kinds of solvents such as alkane, alkene, ketone, lactone, and nitrogen-containing solvent. The thermoreversible gelation of PVdF solution was discussed from the magnitude of interaction parameter $\chi_{12}$ between PVdF and solvent. The parameter $\chi_{12}$ was measured for a concentrated PVdF solution by the usual IGC technique. The parameter $\chi_{12}$ obtained for each PVdF/solvent system increased slowly with decreasing temperature. The present systems were divided broadly into three groups according to the magnitude of $\chi_{12}$ in the vicinity of room temperature, i.e., group (a) with $\chi_{12} \gg 0.5$, group (b) with $\chi_{12} \approx 0.5$, and group (c) with $\chi_{12} \ll 0.5$. The group (b), to which ketone and lactone belong, converted to thermoreversible gels accompanying with crystallization of polymer. The gelation process of PVdF solution was investigated through measurement of in situ Fourier transform infrared (FT-IR) spectroscopy. The time-resolved FTIR spectra suggested that the gelation took place taking the conformation $T_{3} \mathrm{GT}_{3} \overline{\mathrm{G}}$ for the system where the parameter $\chi_{12}$ was nearly equal to 0.5 such as PVdF in $\gamma$-butyrolactone. For the system where the parameter $\chi_{12}$ became larger than 0.5 such as PVdF in cyclohexanone, 3-pentanone, 3-hexanone, 3-heptanone, or 3-octanone, the gelation occurred taking the conformation TGT $\bar{G}$.

KEY WORDS Thermoreversible Gel / Poly(vinylidene fluoride) / Time-Resolved FT-IR / FloryHuggins Interaction Parameter / Inverse Gas Chromatography (IGC) / Sol-Gel Transition /
\end{abstract}

It is well known that the semicrystalline poly $(1,1-$ difluoroethylene) (hereafter named poly(vinylidene fluoride) (PVdF)) takes at least three types of crystalline structures, i.e., $\alpha$-type (conformation: TGTG), $\beta$-type (T), and $\gamma$-type $\left(\mathrm{T}_{3} \mathrm{GT}_{3} \overline{\mathrm{G}}\right)$ structures, depending on the preparation conditions of the polymer such as solution-casting or melt-crystallization techniques. For example, the structure of $\beta$-type crystal can be obtained from the solution-cast film of the $\mathrm{PVdF} /$ hexamethylphosphorictriamide (HMPTA) system, while the $\gamma$-type crystal is obtained by casting from a PVdF/dimethylacetamide (DMA) solution. The $\alpha$-type is known to be the most stable structure, and can be obtained by casting from a $\mathrm{PVdF} /$ acetone solution. Another methods for obtaining these crystalline structures have been also reported. ${ }^{1-6}$

According to the polarity of the bonds between the relatively electron-rich $\mathrm{CH}_{2}$ carbon atoms and the relatively electron-poor $\mathrm{CF}_{2}$ carbon atoms, the repeating unit $\mathrm{CF}_{2} \mathrm{CH}_{2}$ of $\mathrm{PVdF}$ chain has a dipole moment. ${ }^{7}$ As the PVdF polymer shows the ferroelectric behavior, ${ }^{1}$ there is much current interest in solution-casting techniques for fabricating this polymer for sonar and acoustic devices.

Recently, PVdF in some ketones or lactones was found to convert to thermoreversible gel when the solution was cooled to room temperature. This gel is now utilized as binder for positive and negative electrodes in a lithium ion battery. The thermoreversible gelation of crystalline or semicrystalline polymer in solvents is considered to take place in consequence of formation of the network structure whose junction points consist of crystallites. This concept has been widely supported by the X-ray diffraction measurement and kinetics as well as thermodynamics of gel-melting behavior of crystallites. ${ }^{8}$

The structure and physical properties of PVdF gel have been studied by many workers. ${ }^{-13}$ The present authors investigated gelation process of PVdF homopolymer in many organic solvents from measurements of both time-resolved Fourier transform infrared (FT-IR) spectroscopy and dilatometry. ${ }^{14-17}$ Tashiro et al. studied the structural change during the gelation process and the resultant aggregation structure of PVdF polymer and solvent molecules in the gel through measurement of the time-resolved FT-IR. ${ }^{18}$ Hong and Chou studied the relation between phase separation behavior and gelation kinetics in $\mathrm{PVdF} /$ tetra(ethylene glycol) dimethyl ether (TG) solution. ${ }^{19}$ They clarified the effects of the crystallization and phase separation on the gelation of PVdF/TG solution in terms of thermodynamic and kinetic aspects.

In order to discuss more generally whether a PVdF solution converts to thermoreversible gel or not, and 
Thermoreversible Gelation of Poly(vinylidene fluoride)

Table I. Physical properties of PVdF samples

\begin{tabular}{cccccc}
\hline Sample & $\bar{M}_{\mathrm{w}} \times 10^{-4 \mathrm{a}}$ & $\frac{T_{\mathrm{m}}^{\mathrm{b}}}{{ }^{\circ} \mathrm{C}}$ & $\frac{X_{\mathrm{c}}^{\mathrm{c}}}{\%}$ & comonomer & $\frac{\mathrm{HFP}^{\mathrm{d}} \text { content }}{\%}$ \\
\hline Homopolymer & 30.7 & 177.9 & 61.7 & - & - \\
PVdF850 & 37.2 & 177.1 & 60.7 & - & - \\
PVdF1000 & 42.7 & 177.2 & 59.9 & - & - \\
PVdF1100 & 82.7 & 176.7 & 59.0 & - & - \\
PVdF1600 & & & & & \\
Copolymer & 40.0 & 154.8 & 53.6 & HFP $^{\mathrm{d}}$ & 8 \\
PVdF2100 & 25.0 & 138.2 & 39.8 & HFP $^{\mathrm{d}}$ & 12 \\
PVdF2300 &
\end{tabular}

${ }^{a}$ Weight-average molecular weight determined by the intrinsic viscosity in $N, N$-dimethylacetamide (DMA) at $25^{\circ} \mathrm{C}$, using the following equation: ${ }^{32}$ $[\eta]=2.01 \times 10^{-4} \bar{M}_{\mathrm{w}}{ }^{0.675}$. ${ }^{\mathrm{b}}$ Melting temperature measured by DSC. ${ }^{\mathrm{c}}$ Degree of crystallinity estimated from DSC using eq $1 .{ }^{\mathrm{d}}$ Hexafluoropropylene.

furthermore to discuss the stability of $\mathrm{PVdF} /$ organic solvent gel, it is very important to investigate the gelation phenomenon from the viewpoint of the magnitude of interaction between PVdF and solvent. Such thermodynamic study has not been carried out.

In this study, the Flory-Huggins interaction parameter $\left(\chi_{12}\right)$ between PVdF and solvent is estimated from an inverse gas chromatography (IGC) measurement using both homopolymer and copolymer. The correlation between thermoreversible gelation of PVdF solution and the magnitude of $\chi_{12}$ is then examined using a large number of solvents of chemically different groups such as ketone, lactone, alkane, alkene, or nitrogencontaining solvent. Another purpose of this study is to obtain experimentally both sol $\rightarrow$ gel and gel $\rightarrow$ sol transition temperatures as a function of polymer concentration.

\section{EXPERIMENTAL}

\section{Materials}

Four samples of PVdF homopolymers and two samples of copolymers (comonomer is hexafluoropropylene (HFP)), supplied by Kureha Chemical Industry Co., were used. These copolymers are heterogeneous in composition. Physical properties of the samples are summarized in Table I. Each sample has different molecular weight $\left(\bar{M}_{\mathrm{w}}\right)$ and degree of crystallinity $\left(X_{\mathrm{c}}\right)$.

The values of $X_{\mathrm{c}}$ were estimated by means of differential scanning calorimetry (DSC) using the following equation:

$$
X_{\mathrm{c}}[\%]=\left[\Delta H_{\mathrm{m}}{ }^{\mathrm{s}} / \Delta H_{\mathrm{m}}{ }^{*}\right] \times 100
$$

where $\Delta H_{\mathrm{m}}{ }^{\mathrm{s}}$ and $\Delta H_{\mathrm{m}}{ }^{*}$ are the heats of fusion of the present sample and perfectly crystalline PVdF, respectively. A Shimadzu heat flux differential scanning calorimeter (Model DSC-50) was used for measurement of $\Delta H_{\mathrm{m}}$ s after calibration with standard indium
$\left(T_{\mathrm{m}}=156.6^{\circ} \mathrm{C} ; \Delta H_{\mathrm{m}}=28.5 \mathrm{~J} \mathrm{~g}^{-1}\right)$. All DSC experiments were carried out at a heating rate of $10^{\circ} \mathrm{C} \mathrm{min}^{-1}$ under a constant flow of $\mathrm{N}_{2}$ gas. In this study, a value of $104.7 \mathrm{~J} \mathrm{~g}^{-1}$ was used for $\Delta H_{\mathrm{m}}{ }^{*}$ in eq 1 , whose value was reported by Rosenberg et al. ${ }^{20}$

The solvents (probes) used were hexane, $m$-xylene, 3-pentanone, 3-hexanone, 3-heptanone, 3-octanone, cyclohexanone, $\gamma$-butyrolactone, $N, N$-dimethylacetamide (DMA), and $N$-methyl-2-pyrrolidinone (NMP). These solvents are reagent grade, and were used without further purification.

\section{Inverse Gas Chromatography (IGC)}

The interaction parameter $\chi_{12}$ between polymer and solvent was estimated by an IGC measurement. According to the IGC method, the parameter $\chi_{12}$ can be obtained easily over wide range of temperature. The column preparation was carried out as follows: A definite amount of PVdF sample was dissolved completely in dimethylformamide (DMF) under stirring. As a support, Chromosorb WAW-DMCS 60/80 mesh was used, which is a good solid support for IGC measurement. The coating with PVdF was carried out by the method recommended by Al-Saigh and Munk. ${ }^{21,22} \mathrm{~A}$ PVdF/DMF solution was deposited on the Chromosorb. The solution on the Chromosorb was evaporated by gentle stirring and heating on a hot plate.

A solid support (Chromosorb) coated with PVdF sample was dried under reduced pressure at $50^{\circ} \mathrm{C}$ for $24 \mathrm{~h}$, and packed tightly into a stainless steel column with $2.2 \mathrm{~mm}$ in diameter and $2 \mathrm{~m}$ in length. The weight of polymer ( $W$ in eq 2 ) in the column was determined by weighing of the column before and after coating. An IGC experiment was carried out by increasing the column temperature using a GL Science GC-380 type gas chromatograph equipped with a flame ionization detector (FID). Helium gas was used as a carrier, while methane gas was used as a noninteracting marker. The 
helium carrier gas was introduced at a flow rate of $25 \mathrm{~mL} \mathrm{~min}^{-1}$. The retention time ( $\Delta t$ in eq 3 ) was determined from the difference between maximum peaks of marker $t_{\mathrm{M}}\left(\mathrm{CH}_{4}\right.$ gas) and probe $t_{\mathrm{P}}$ (solvent).

\section{Fourier Transform Infrared Measurement}

The FT-IR measurement of a PVdF solution was carried out using a JASCO FT-IR spectrometer, Model FT/IR-660. A PVdF solution with the given concentration was poured into a KRS-5 cell placed in the FT-IR spectrometer. The FT-IR spectra were recorded by the ATR (attenuated total reflection) method at intervals of $10 \mathrm{~s}$ with the wavelength resolution of $4 \mathrm{~cm}^{-1}$.

\section{Sol $\rightarrow$ Gel and Gel $\rightarrow$ Sol Transition Temperatures}

Sol $\rightarrow$ gel transition temperatures were determined as follows: A PVdF solution $\left(170^{\circ} \mathrm{C}\right)$ with a given concentration in a sealed glass tube ( $c a .35 \mathrm{~cm}$ in length and $1 \mathrm{~cm}$ in diameter) was immersed in a thermobath kept at an appropriate temperature $\left(T_{\text {gel }}\right)$ for $12 \mathrm{~h}$. A steel ball of $c a .30 \mathrm{mg}$ weight with $2 \mathrm{~mm}$ in diameter was then put on the surface of the $\mathrm{PVdF} /$ solvent system in the glass tube to examine whether it would ride or not. If so, such a system was defined as a gel. When the steel ball moved downwards, such a system was defined as a sol and the system was heated once more at $170^{\circ} \mathrm{C}$ in order to dissolve the polymer. The same measurement was then repeated lowering the gel-forming temperature $T_{\text {gel }}$ of the thermobath.

Gel $\rightarrow$ sol transition (gel-melting) temperature $\left(T_{\mathrm{m}}{ }^{\mathrm{g}}\right)$ was measured by the ball-drop method using a steel ball of $c a .30 \mathrm{mg}$ weight, whose size did not influence $T_{\mathrm{m}}{ }^{\mathrm{g}}$. A PVdF solution at elevated temperature $\left(170^{\circ} \mathrm{C}\right)$ in a sealed glass tube was cooled at $30^{\circ} \mathrm{C}$ for $12 \mathrm{~h}$ to prepare a gel. The gel in the glass tube was heated at $c a$. $0.3^{\circ} \mathrm{C} \mathrm{min}-1$, while the height of the steel ball placed on the surface of gel layer was recorded by a cathetometer as a function of temperature. The gel-melting temperature $T_{\mathrm{m}}^{\mathrm{g}}$ was determined by the method proposed by Takahashi. ${ }^{23}$

\section{RESULTS AND DISCUSSION}

\section{The Flory-Huggins Interaction Parameter}

The retention volume $\left(V_{\mathrm{g}}\right)$ at polymer loading $W$ in the column was calculated using the following equation ${ }^{24}$ :

$$
V_{\mathrm{g}}=\frac{\Delta t \times F \times\left(P_{0}-P_{\mathrm{w}}\right) \times(273.15)}{W \times P_{0} \times T_{\mathrm{r}}} \times \frac{3\left[\left(P_{\mathrm{i}} / P_{\mathrm{w}}\right)^{2}-1\right]}{2\left[\left(P_{\mathrm{i}} / P_{\mathrm{w}}\right)^{3}-1\right]}
$$

with

$$
\Delta t=t_{\mathrm{P}}-t_{\mathrm{M}}
$$

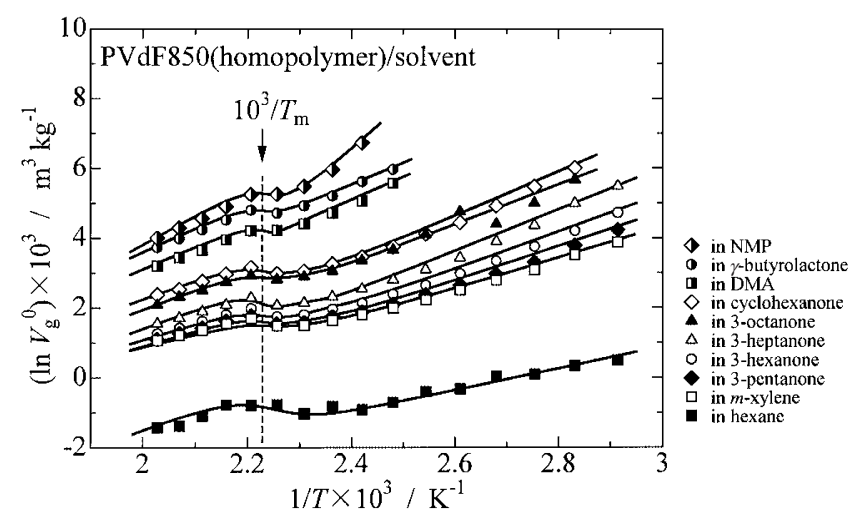

Figure 1. Relation between $\ln V_{\mathrm{g}}^{0}$ and reciprocal of temperature $(1 / T)$, where $V_{\mathrm{g}}{ }^{0}$ is the specific retention volume.

where

$V_{\mathrm{g}}\left[\mathrm{mL} \mathrm{g}^{-1}\right]$ : retention volume;

$F\left[\mathrm{~mL} \mathrm{~s}^{-1}\right]$ : flow rate of carrier gas;

$P_{\mathrm{o}}[\mathrm{Pa}]$ : pressure of outlet;

$P_{\mathrm{w}}[\mathrm{Pa}]$ : vapor pressure of water at room temperature $T_{\mathrm{r}}$

$P_{\mathrm{i}}[\mathrm{Pa}]:$ pressure of inlet;

$W[\mathrm{~g}]$ : weight of polymer;

$T_{\mathrm{r}}[\mathrm{K}]$ : room temperature;

$t_{\mathrm{P}}[\mathrm{s}]$ : retention time of probe;

$t_{\mathrm{M}}[\mathrm{s}]$ : retention time of marker.

The retention volume $V_{\mathrm{g}}$ calculated by eq 2 was extrapolated to infinite loading in order to obtain the specific retention volume $\left(V_{\mathrm{g}}{ }^{0}\right)$. The retention diagram was obtained as shown in Figure 1 by plotting logarithm of $V_{\mathrm{g}}{ }^{0} v$. reciprocal of the absolute temperature $(1 / T)$. As seen in Figure 1, a Z-shaped curve was obtained for each $\mathrm{PVdF} /$ solvent system and a retention diagram was nearly linear before and after the reciprocal of melting temperature of the sample $\left(10^{3} / T_{\mathrm{m}}\right.$ shown in Figure 1). It is well known that this behavior is characteristic for crystalline or semicrystalline polymers. ${ }^{24,25}$

The Flory-Huggins interaction parameter $\chi_{12}$ was calculated by the following equation ${ }^{24}$ using the data $V_{\mathrm{g}}{ }^{0}$ in Figure 1:

$$
\chi_{12}=\ln \frac{(273.15) \times R \times V_{2}}{V_{\mathrm{g}}^{0} \times V_{1} \times P_{1}^{0}}-1-\frac{P_{1}^{0}}{R \times T}\left(B_{11}-V_{1}\right)
$$

where

$V_{1}\left[\mathrm{~m}^{3} \mathrm{~mol}^{-1}\right]$ : molar volume of probe;

$P_{1}^{0}\left[\mathrm{~J} \mathrm{~m}^{-3}\right]$ : vapor pressure of probe;

$V_{2}\left[\mathrm{~m}^{3} \mathrm{~kg}^{-1}\right]$ : specific volume of polymer at column temperature;

$R\left[\mathrm{~J} \mathrm{Kmol}^{-1}\right]$ : gas constant;

$B_{11}\left[\mathrm{~m}^{3} \mathrm{~mol}^{-1}\right]$ : the second virial coefficient of probe in a gaseous state;

$V_{\mathrm{g}}^{0}\left[\mathrm{~m}^{3} \mathrm{~kg}^{-1}\right]$ : specific retention volume.

The values of $V_{1}, P_{1}^{0}$, and $B_{11}$ in eq 4 were calculated 
using the method reported by Daubert and Danner. ${ }^{26}$ The parameter $\chi_{12}$ thus obtained for many kinds of solvents was plotted against temperature $T$ as shown in Figure 2, which is the data of copolymer (PVdF2300). As seen in Figure 2, the parameter $\chi_{12}$ increased slowly with decreasing temperature for any solvent. That is, each solvent behaves as a poor solvent for PVdF with decreasing temperature.

The characteristic result is that the present systems are classified broadly into three groups, i.e., group (a), (b), and (c), according to the magnitude of $\chi_{12}$ in the vicinity of room temperature as shown in Figure 2:

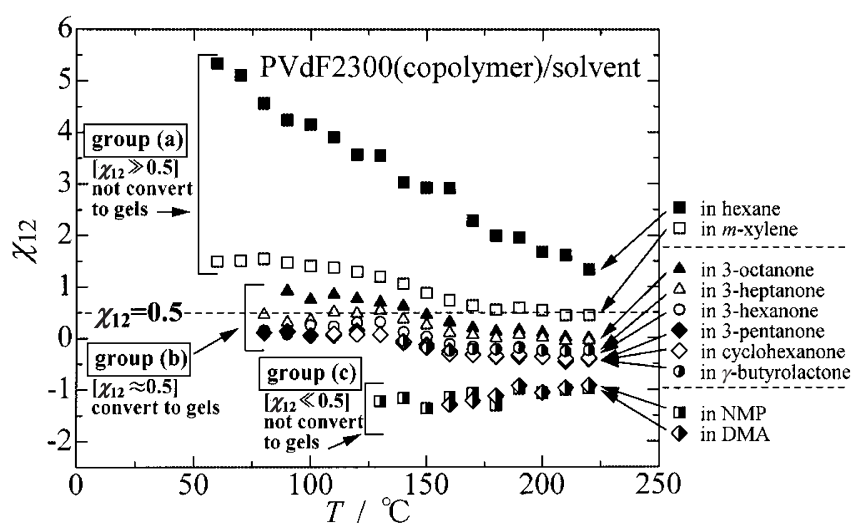

Figure 2. Relation between the Flory-Huggins interaction parameter $\left(\chi_{12}\right)$ and temperature $(T)$, which was measured for the sample PVdF2300 (copolymer) in ten kinds of organic solvents.
(1) Solvents in the group (a) are alkane and alkene such as hexane and $m$-xylene, and this group shows $\chi_{12} \gg 0.5$; (2) Solvents in the group (b) are ketones and lactone such as 3-octanone, 3-heptanone, 3-hexanone, 3-pentanone, cyclohexanone, and $\gamma$-butyrolactone, and this group shows $\chi_{12} \approx 0.5$; (3) Solvents in the group (c) are polar solvents such as NMP and DMA, and this group shows $\chi_{12} \ll 0.5$. According to the measurement by the ball-drop method, $\mathrm{PVdF} /$ organic solvent systems in the group (b) were found to convert to thermoreversible gels near room temperature. The group (a) caused macroscopically the liquid/solid phase separation and crystalline precipitates were separated from a solution with cooling, while the group (c) showed one phase solution even if the PVdF/NMP and PVdF/DMA solutions were cooled to room temperature.

\section{In situ FT-IR Spectra}

In the above section, we reported that the $\mathrm{PVdF} /$ organic solvent systems with $\chi_{12} \approx 0.5$ converted to thermoreversible gels. It is very interesting to investigate the gelation process of the $\mathrm{PVdF} /$ solvent systems having different values of $\chi_{12}$. The gelation process was investigated by in situ FT-IR method. Figure 3 shows the time-resolved FT-IR spectra obtained for the sample PVdF850 (homopolymer) in (a) cyclohexanone and (b) $\gamma$-butyrolactone. In Figure $3 \mathrm{c}$, PVdF850 in hexane, $m$-xylene, NMP, and DMA did

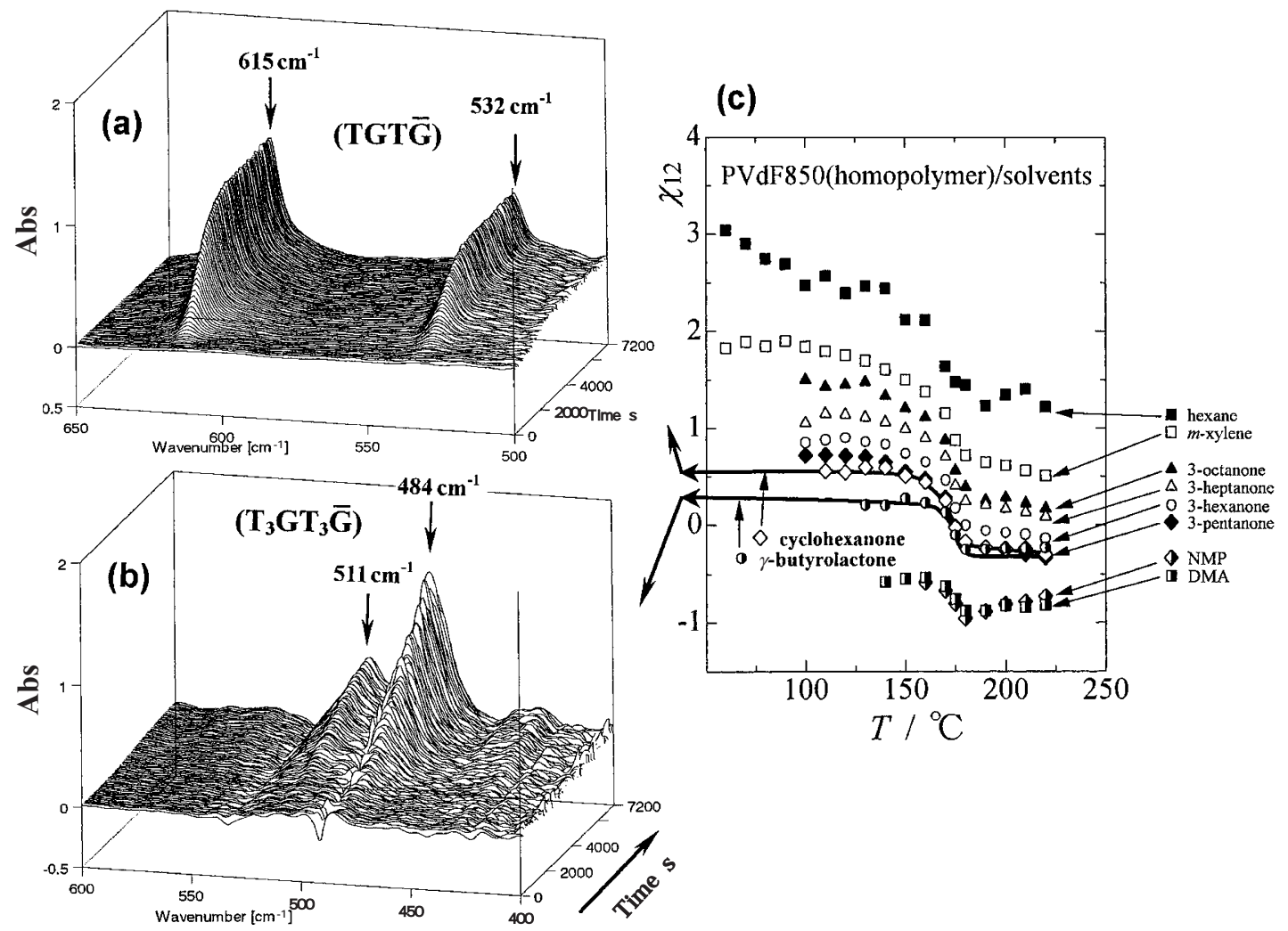

Figure 3. Time dependence of FT-IR spectra obtained for the sample PVdF850 (homopolymer) in (a) cyclohexanone and (b) $\gamma$ butyrolactone; and (c) relation between $\chi_{12}$ and temperature $(T)$ of PVdF850 in various solvents. 
not convert to gel, but did so in $\gamma$-butyrolactone, cyclohexanone, 3-pentanone, 3-hexanone, 3-heptanone, and 3-octanone. As seen in Figure 3c, the FloryHuggins interaction parameter $\chi_{12}$ of PVdF850 in cyclohexanone is larger than that in $\gamma$-butyrolactone. That is, cyclohexanone behaves as more poor solvent than $\gamma$ butyrolactone.

The region $400-600 \mathrm{~cm}^{-1}$ is known to be sensitive to the PVdF conformation. ${ }^{1,27}$ In Figure 3a, strong vibrational bands near $615 \mathrm{~cm}^{-1}$ and $532 \mathrm{~cm}^{-1}$ are observed, and become larger with increasing time. These bands are known to be due to the formation of the conformation TGT $\overline{\mathrm{G}}$. Besides the PVdF850/cyclohexanone system, the same absorption bands were also observed for PVdF850 in other ketones such as 3-pentanone, 3hexanone, 3-heptanone, or 3-octanone. On the other hand, the absorption bands at $511 \mathrm{~cm}^{-1}$ and $484 \mathrm{~cm}^{-1}$ in Figure $3 \mathrm{~b}$ are known to be due to the formation of the conformation $\mathrm{T}_{3} \mathrm{GT}_{3} \overline{\mathrm{G}}$.

Therefore, it was found from both $\chi_{12}$ and in situ FT-IR measurements that the thermoreversible gelation of PVdF took place taking the conformation $T_{3} \mathrm{GT}_{3} \overline{\mathrm{G}}$ for the system where the interaction between PVdF and solvent is relatively large such as the $\mathrm{PVdF} / \gamma$ butyrolactone system. While, gelation took place taking the conformation TGT $\overline{\mathrm{G}}$ for the system where the interaction becomes smaller $\left(\chi_{12}>0.5\right)$ such as $\mathrm{PVdF}$ in cyclohexanone, 3-pentanone, 3-hexanone, 3heptanone, or 3-octanone.

In the previous study, ${ }^{14}$ the present authors measured the gelation times $\left(t_{\text {gel }}\right)$ of two systems: $\mathrm{PVdF} / \gamma$ butyrolactone and PVdF/cyclohexanone. In that study, $t_{\text {gel }}$ of PVdF in cyclohexanone was found to be smaller than that in $\gamma$-butyrolactone. That is, the completion of gelation in cyclohexanone was faster than that in $\gamma$-butyrolactone. Taking account of these results, it may be possible to suppose that PVdF random coil chains in a relatively poor solvent such as cyclohexanone gather quickly to crystallize because of small interaction between PVdF and solvent. It is expected, therefore, that the formation of TGTG conformation is induced rapidly and, as a result, gelation accompanying with crystallization takes place fast. On the contrary, crystallization of polymers is delayed in $\gamma$ butyrolactone because the interaction between PVdF and solvent is large. Accordingly, it is considered that gelation accompanying with crystallization of polymers in $\gamma$-butyrolactone takes place slowly.

\section{Sol $\rightarrow$ Gel and Gel $\rightarrow$ Sol Transition Temperatures}

Figures 4 and 5 show sol $\rightarrow$ gel transition (gelforming) and gel $\rightarrow$ sol transition (gel-melting) temperatures as a function of PVdF concentration in $\gamma$ -

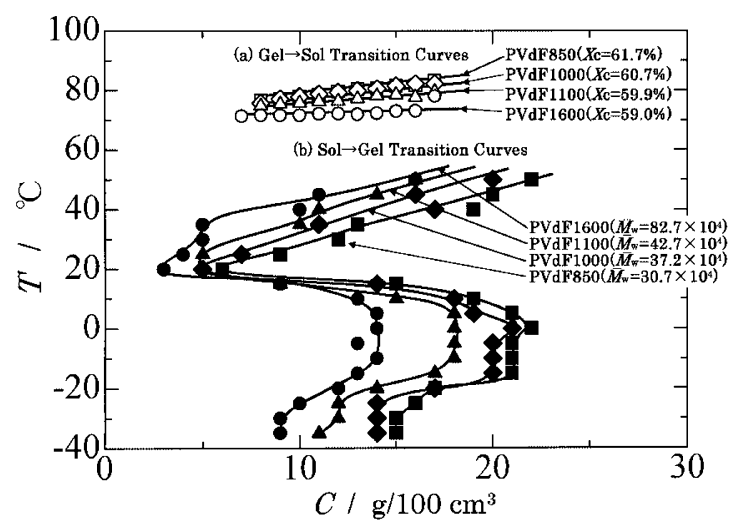

Figure 4. (a) Gel $\rightarrow$ sol transition curves and (b) sol $\rightarrow$ gel transition curves measured in $\gamma$-butyrolactone.

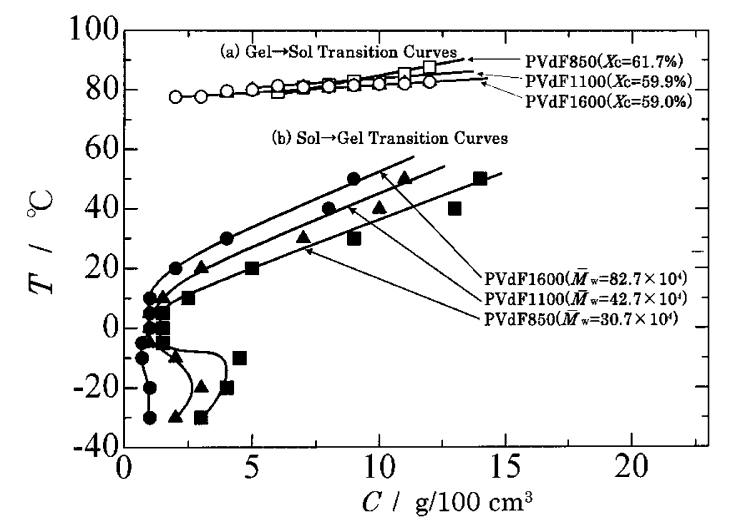

Figure 5. (a) Gel $\rightarrow$ sol transition curves and (b) sol $\rightarrow$ gel transition curves measured in cyclohexanone.

butyrolactone and cyclohexanone. As seen in Figure $4 \mathrm{~b}$, the sol $\rightarrow$ gel transition curve obtained for each sample showed an S-shaped curve. In the temperature region $T>20^{\circ} \mathrm{C}$, the sol $\rightarrow$ gel transition temperature showed the lowest value near $20^{\circ} \mathrm{C}$ without regard to the difference in sample. In other words, a gel having the lowest concentration was formed in the vicinity of $20^{\circ} \mathrm{C}$. As a whole, the sol $\rightarrow$ gel transition curve shifted to lower concentration with increasing molecular weight of $\bar{M}_{\mathrm{w}}$ of sample. In Figure $5 \mathrm{~b}$, the similar tendency was obtained as in Figure $4 \mathrm{~b}$.

The gel $\rightarrow$ sol transition (gel-melting) temperatures are shown in Figure 4a and 5a. The gel-melting temperature $\left(T_{\mathrm{m}} \mathrm{g}\right)$ of each sample increases gradually with increasing polymer concentration similar to highly crystalline polymer gel such as polyethylene or isotactic polypropylene gel. ${ }^{28-30}$ The molecular weight dependence of $T_{\mathrm{m}}{ }^{\mathrm{g}}$ is not observed in Figure 4a and 5a. It is likely seen that the gel $\rightarrow$ sol transition curve becomes higher with increasing $X_{\mathrm{c}}$ of sample, though the difference in $X_{\mathrm{c}}$ of the present PVdF samples is not so large.

As seen in Figures $4 \mathrm{~b}$ and $5 \mathrm{~b}$, the sol $\rightarrow$ gel transition curve of PVdF sample showed a unique behavior. Kaji et al. measured the sol $\rightarrow$ gel transition curves of atactic poly(vinyl alcohol) (at-PVA) in a mixture of dimethyl 
sulphoxide (DMSO) and water $(60 / 40 \mathrm{vol} / \mathrm{vol})$ as a function of at-PVA molecular weight. ${ }^{31}$ The transition curves of at-PVA are very similar to the present curves of PVdF/organic solvent systems.

As a PVdF sample is a semicrystalline polymer, the sol $\rightarrow$ gel transition temperatures may be influenced by the effect of crystallization of polymer. Moreover, the present system is cooled near room temperature and thus it is expected that liquid/liquid phase separation caused by the spinodal decomposition may take place at the early stage of crystallization. Therefore, it is strongly suggested that the sol $\rightarrow$ gel transition of PVdF/organic solvent system takes place through competition between liquid/liquid phase separation and crystallization. In order to discuss more detail the sol $\rightarrow$ gel transition curve of PVdF, spinodal decomposition as well as binodal lines must be measured. These problems are left for future study.

\section{CONCLUSION}

The present study clarified the following results for the sol-gel transition of PVdF in organic solvents through measurements of time-resolved FT-IR spectrum and polymer/solvent interaction parameter:

1 . The Flory-Huggins interaction parameter $\chi_{12}$ estimated for PVdF/organic solvent systems were divided into three groups according to the magnitude of $\chi_{12}$ in the vicinity of room temperature, i.e., $\chi_{12} \approx 0.5$, $\chi_{12} \gg 0.5$, and $\chi_{12} \ll 0.5$. The thermoreversible gelation took place taking the conformation $\mathrm{T}_{3} \mathrm{GT}_{3} \overline{\mathrm{G}}$ in a system where the parameter $\chi_{12}$ was nearly equal to 0.5 . In a system where the parameter $\chi_{12}$ became larger than 0.5 , the gelation occurred taking the conformation TGT $\bar{G}$. In a system where $\chi_{12} \gg 0.5$ or $\chi_{12} \ll 0.5$, no gelation occurred.

2 . The sol $\rightarrow$ gel transition (gel-forming) curve shifted to lower concentration with increasing molecular weight, while the gel $\rightarrow$ sol transition (gel-melting) curve became higher with increasing degree of crystallinity of PVdF sample.

Acknowledgment. This study was supported by the Grant-in-Aid for Scientific Research (C) from the Japan Society for the Promotion of Science under grant number 12650891 .

\section{REFERENCES}

1. K. Tashiro, "Ferroelectric Polymers: Chemistry, Physics, and Applications”, H. S. Nalwa, Ed., Marcel Dekker, Inc., New York, N.Y., 1995, p 63.

2. K. Tashiro, H. Tadokoro, and M. Kobayashi, Ferroelectrics,
32, 167 (1981).

3. W. W. Doll and J. B. Lando, J. Macromol. Sci., Phys., B4(2), 309 (1970).

4. R. Hasegawa, M. Kobayashi, and H. Tadokoro, Polym. J., 3, 591 (1972).

5. A. J. Lovinger, Macromolecules, 15, 40 (1982).

6. L. J. Fina, J. L. Koenig, and W. L. Gordon, J. Polym. Sci., Part B: Polym. Phys., 24, 2541 (1986).

7. D. Geiss and D. Hofmann, Prog. Polym. Sci., 15, 57 (1990).

8. A. Takahashi, T. Nakamura, and I. Kagawa, Polym. J., 3, 207 (1972).

9. M. Tazaki, A. Onodera, and T. Homma, Kobunshi Ronbunshu, 50, 533 (1993).

10. M. Tazaki and T. Homma, Kobunshi Ronbunshu, 53, 482 (1996).

11. J. W. Cho, H. Y. Song, and S. Y. Kim, Polymer, 34, 1024 (1993).

12. S. Mal, P. Maiti, and A. K. Nandi, Macromolecules, 28, 2371 (1995).

13. A. K. Dikshit and A. K. Nandi, Macromolecules, 33, 2616 (2000).

14. M. Tazaki, R. Wada, M. Okabe, and T. Homma, J. Appl. Polym. Sci., 65, 1517 (1997).

15. Y. Sato, R. Wada, M. Tazaki, and M. Okabe, Nippon Kagaku Kaishi, 481 (1998).

16. R. Wada, Y. Sato, M. Tazaki, and M. Okabe, Nippon Kagaku Kaishi, 253 (1999).

17. R. Wada, K. Aihara, H. Nomoto, M. Tazaki, and M. Okabe, Nippon Kagaku Kaishi, 797 (2000).

18. K. Tashiro, F. Joubert, K. Fukuda, and F. Kaneko, Polym. Prepr. Jpn., 47, 3811 (1998).

19. P.-D. Hong and C.-M. Chou, Polymer, 41, 8311 (2000).

20. For example, Y. Rosenberg, A. Siegmann, M. Narkis, and S. Shkolnik, J. Appl. Polym. Sci., 43, 535 (1991).

21. C.-T. Chen and Z. Y. Al-Saigh, Polymer, 31, 1170 (1990).

22. P. Munk, P. Hattam, Q. Du, and A. A. Adbel-Azim, J. Appl. Polym. Sci., Appl. Polym. Symp., 45, 289 (1990).

23. A. Takahashi, M. Sakai, and T. Kato, Polym. J., 12, 335 (1980).

24. J. R. Conder and C. L. Young, "Physicochemical Measurement by Gas Chromatography", John Wiley \& Sons, Inc., New York, N.Y., 1979.

25. For example, J. F. Rabek, "Inverse Gas Chromatography", in "Experimental Methods in Polymer Chemistry", WileyInterscience, New York, N.Y., 1980, chapt. 24.

26. T. E. Daubert and R. P. Danner, Eds., "Physical and Thermodynamic Properties of Pure Chemicals, Data Compilation", Hemisphere Publishing, Corp., New York, N.Y., 1989.

27. E. Benedetti, A. D'Alessio, C. Bertolutti, P. Vergamini, N. D. Fanti, M. Pianca, and G. Moggi, Polym. Bull., 22, 645 (1989).

28. H. Matsuda, T. Inoue, M. Okabe, and T. Ukaji, Polym. J., 19, 323 (1987).

29. M. Okabe and A. Takahashi, Polym. J., 30, 883 (1998).

30. M. Okabe, K. Mitsui, F. Sasai, and H. Matsuda, Polym. J., 21, 313 (1989).

31. M. Ohkura, T. Kanaya, and K. Kaji, Polymer, 33, 3686 (1992).

32. G. J. Welch, Polymer, 15, 429 (1974). 